\title{
Green Synthesis of Zinc Oxide Nanoparticles via Algal Route and its Action on Cancerous Cells and Pathogenic Microbes
}

\author{
Priyankari Bhattacharya*1, Kasturi Chatterjee ${ }^{2}$, Snehasikta Swarnakar², Sathi Banerjee ${ }^{1}$ \\ ${ }^{1}$ Metallurgical and Materials Engineering Department, Jadavpur University, Kolkata 700032, India \\ ${ }^{2}$ Drug Development Diagnostics \& Biotechnology Division, CSIR-Indian Institute of Chemical Biology, \\ Kolkata 700032 \\ * Corresponding author email: priyankari2004@yahoo.co.in, Tel.: +91 3324572227
}

Received: 29 May 2020 / Revised: 21 June 2020 / Accepted: 29 June 2020 / Published: 05 July 2020

\begin{abstract}
Application of metal oxide nanoparticles for treatment of melanoma cells and microbes is being investigated. Zinc oxide nanoparticles ( $\mathrm{ZnO}$ NPs) deserve special mention where particles cause destruction of melanoma cells with minimal damage to healthy cells. In the present study, pure phase $\mathrm{ZnO}$ NPs with particle size of $3.1 \mathrm{~nm}$ were synthesized by green route using algal extract. Skin melanoma (B16F10) cells were treated with synthesized ZnO NP and compared with commercial $\mathrm{ZnO}$ NPs and analysed for ED50 for cellular viability using 3\% (w/v) of the doses. Sensitivity of B16F10 cells towards green synthesized $\mathrm{ZnO}$ NP was found to be more than commercial ZnO NPs. Results showed greater reduction in viability of cells exposed to green synthesized ZnO NPs and with increasing dose of the $\mathrm{ZnO} N \mathrm{NP}$, percentage viability of cells gradually reduced. $50 \%$ decrease in cellular viability (ED50) was obtained for green synthesized $\mathrm{ZnO} N \mathrm{NP}$ at 3\% dose while commercial $\mathrm{ZnO}$ exhibited ED50 at $6 \%$ of doses. The ZnO NP also showed antimicrobial activity against Pseudomonas sp. and Staphylococcus sp. Zone of inhibition (ZOI) exhibited by Pseudomonas aeruginosa and Staphylococcus aureus for disc diffusion and well diffusion assay was around 10-22 $\mathrm{mm}$ and $9-12 \mathrm{~mm}$ respectively.
\end{abstract}

Keywords: ZnO NPs; green synthesis; Antimicrobial; melanoma cells; destruction of tumor cells.

\section{Introduction}

Nanoscience deals with the fine tuning of material properties so as to control size and shape of materials. The particles thus developed are known as nanoparticles ranging within particle size from 1 to $100 \mathrm{~nm}$ [1]. Advances in nanotechnology resulted in different types of nanoparticles having diverse chemical and physical properties. These nanoparticles are engineered to have desired selectivity, size, shape and biocompatibility. Nanoparticles are also used as media in drug delivery as they are engineered to be $\mathrm{pH}$ sensitive [2]. To increase biocompatibility of orthopedic implants, nanoparticles are being used [3]. Cancer is uncontrolled growth of abnormal cells that infiltrates normal body cells. Treatment includes chemotherapy, radiotherapy, surgery etc. 'which poses serious after effects. Nanomedicines developed from metal oxide nanoparticles having high biocompatibility, lesser toxicity and surface functionalization are being widely used for targeted drug delivery for cancer cell treatment. Nanomaterials are known to destroy tumor cells by generation of ROS reduce its mass [4]. They can diffuse into cancerous cells due to the leaky vasculature nature of the cells and cause its apoptosis. Metal oxide nanoparticles are directly used to kill tumor cells [5]. Among various metal oxide nanoparticles widely used, zinc oxide nanoparticles ( $\mathrm{ZnO}$ NPs) have been exploited in field of biotechnology, biomedical research, drug delivery, cellular imaging etc. because of their low toxicity and biodegradability. Zinc is an essential nutrient and is safe for invivo applications [6]. ZnO NPs are present in sunscreens, cosmetics, food packaging, paints etc. [7]. ZnO dissolves slowly in acidic conditions i.e. in tumour cells and in basic condition and releases zinc ion causing 
Green Synthesis of Zinc Oxide Nanoparticles via Algal Route and its Action on Cancerous Cells and Pathogenic Microbes

apoptosis [8]. This makes $\mathrm{ZnO} \mathrm{NP}$ suitable for biomedical applications [9]. It has been studied that zinc maintains the activity of p53 which is tumor suppressor gene as well as helps in activation of caspase-6 enzyme thereby regulating apoptosis [10]. Wang et al., reported use of $\mathrm{ZnO}$ to be effective against cancer cells as it might generate reactive oxygen species (ROS) in cells thereby destroying it [11]. Taninio et al., studied $\mathrm{ZnO}$ in vitro against human small-cell lung cancer as well as in orthotopic mouse models. The authors observed the potential of $\mathrm{ZnO}$ by intravenously administering invivo against orthotopic small-cell lung cancers without any adverse effect. Studies have shown $\mathrm{ZnO}$ to be more cytotoxic towards cancer cells than healthy cells due to more permeation and retention of the particles by cancer cells [12]. ZnO NPs have shown to be highly effective on T98G cancer cells, moderately effective on $\mathrm{KB}$ cells, and less toxic on normal human HEK cells [13]. ZnO NPs increases mitotic i.e. cytogenetic damage and interphase i.e. apoptosis death. They induce micronucleus formation in cells thereby helping in designing potent anticancer drugs [14]. Intracellular ROS production of melanoma cancer cells was measured with varying dose of $\mathrm{ZnO}$ NPs. It was observed that the nanoparticle was effective against HepG2 (liver cancer) and MCF-7(breast cancer) cells with less than $10 \%$ cell viability with $25 \mu \mathrm{g} / \mathrm{mL}$ nanoparticles dose [15]-[16]. Apart from being a potential anticancer candidate $\mathrm{ZnO}$ also affects growth of both gram positive and gramnegative bacteria [17]. The nanoparticles are sensitive towards the lipid bilayer of bacteria resulting in generation of ROS and cell destruction [18].

Synthesis of $\mathrm{ZnO}$ NPs generally involves use of chemicals through various methods like direct precipitation, homogeneous precipitation, solvo-thermal method, sono-chemical method, reverse micelles, sol gel method, hydrothermal, thermal decomposition, and microwave irradiation etc [19]-[20]. Green synthesis of metal oxide nanoparticles is nowadays being widely used for their cost effectiveness and lower toxicity. $\mathrm{ZnO} \mathrm{NPs}$ synthesized from green route are assumed to be more biocompatible than that synthesized from chemical and physical methods [5]. ZnO nanoparticles have been synthesized using milky latex of Calotropis procera, Aloe vera, Parthenium hysterophorus, Plectranthus amboinicus, Trifolium pratense flower extract etc. [21]-[22].

In the present study, green synthesis of $\mathrm{ZnO} N \mathrm{Ns}$ was carried out using algal extracts (Anabaena cylindrica) obtained from Institute of Biotechnology, Kolkata, India. Anabaena cylindrica belongs to group of cyanobacteria or blue-green algae and are photosynthetic in nature and fixes nitrogen. Biologically active compounds like mannose rich carbohydrate, amino acids, lipids etc. are present in Anabaena sp. which acts as reducing and capping agents in green synthesis of nanoparticles [23]- [24]. This alga has been used for synthesis of copper oxide nanoparticles for drinking water treatment [25]. Namvar et al., have studied formation of $\mathrm{ZnO}$ NPs via green route using brown seaweed, Sargassum muticum and observed its anticancer activity on murine cancer cell lines [24].

In this study, anticancerous activity of the green synthesized zinc oxide nanoparticles ( $\mathrm{ZnO} \mathrm{NPs}$ ) was observed in skin melanoma cell line (B16F10) obtained from National Centre for Cell Science, Pune, India and compared the results with commercial $\mathrm{ZnO}$ NPs. Among different metal oxide nanoparticles, zinc is more effective for destruction of cancer cells. Zinc Antimicrobial activity of ZnO NPs was observed against Streptococcus aureus, a gram positive bacteria that causes skin infection, respiratory tract infection and food poisoning in humans and Pseudomonas aeruginosa, a gram negative bacteria known to cause serious illnesses i.e. hospital-acquired infections like ventilator-associated pneumonia and various sepsis.

\section{Materials and methods}

\subsection{Preparation of algal extract}

Pure strain of Anabaena cylindrica was obtained from a biotechnology Institute, Kolkata, India. Algae were cultured under aseptic conditions with proper illumination and at room temperature inside laminar chamber. Algal extract was prepared by boiling dried biomass in distilled water. Extract was then sterilized by autoclaving and stored for synthesis of nanoparticles. 


\subsection{Green synthesis of zinc oxide nanoparticles}

Zinc sulphate $\left(\mathrm{ZnSO}_{4} .7 \mathrm{H}_{2} \mathrm{O}\right.$, Merck, India) was used as starting material for nanoparticle synthesis. Algal extract (1:1) was added drop wise to $100 \mathrm{ml}$ of sterilized $1 \mathrm{mM}$ zinc sulphate solution. Solution was stirred inside laminar air chamber at 700rpm, $\mathrm{pH}$ of the solution being kept at 8.4. The particles produced were washed for neutralization, dried overnight at $100^{\circ} \mathrm{C}$ and kept in sterile air tight container for further use. Commercial zinc oxide nanoparticles were purchased from Sigma Aldrich having particle size of $<50 \mathrm{~nm}$.

\subsection{Characterization of $\mathrm{ZnO}$ NPs}

Synthesized nanoparticles were characterized to observe phase purity for application on cell line. XRD (Xray diffraction) analysis of synthesized nanoparticles were carried out and recorded with varying $2 \theta\left(10^{\circ}\right.$ $80^{\circ}$ ) at $25^{\circ} \mathrm{C}$ in XPERTPRO diffractometer (Philips, PANalytical, Holland) to understand the nature of nanoparticles formed. To understand the structural morphology of nanoparticles, FESEM (Field emission scanning electron microscope) analysis was performed and recorded microscope (Gemini Zeiss Supra ${ }^{\mathrm{TM}}$ 35VP, Carl Zeiss, Germany). Surface area of nanoparticles was determined in Autosorb1, Quantachrome Instruments (USA). FTIR (Fourier transform infrared spectroscopy) spectra were recorded in the range between 400 and $4000 \mathrm{~cm}^{-1}$ for determining functional groups present in nanoparticles. Information in size, shape, particle morphology and composition of particles was obtained from Transmission electron microscopic analysis (TEM, Technai G2 30ST, FEI Company, USA). XPS (X-ray photoelectron spectroscopy) analysis was performed to understand the chemical state and composition of nanoparticles and scanned within binding energy of 0-1100 electron volts (eV) (5000 XPS-analyzer, Versaprobe-II, USA).

\subsection{Anti-microbial activity of ZnO NPs}

Antimicrobial activity of green synthesized $\mathrm{ZnO}$ NPs was observed against gram-positive bacteria Staphylococcus aureus and gram-negative bacteria Pseudomonas aeruginosa by both disc assay and well diffusion method. Mueller-Hinton agar was used as growing media for bacteria. The media was poured in Petri plates of about $90 \mathrm{~mm}$ thickness and streaked with respective bacteria in triplicates. Paper discs of about $6 \mathrm{~mm}$ diameter impregnated with $100 \mu \mathrm{L}$ of $0.015 \mathrm{mg} / \mathrm{ml} \mathrm{ZnO} \mathrm{NPs} \mathrm{dose} \mathrm{and} \mathrm{was} \mathrm{placed} \mathrm{on} \mathrm{agar} \mathrm{plates} \mathrm{sparing}$ control. The dose was determined from MIC where nanoparticles dose was varied from $0-0.06 \mathrm{mg} / \mathrm{ml}$. For well diffusion assay, $4 \mathrm{~mm}$ size cavity was bored on solidified agar plates containing streaked bacterial cells and $100 \mu \mathrm{L}$ dose of $\mathrm{ZnO}$ NPs was poured in each well except for control. Plates were then incubated at $37^{\circ} \mathrm{C}$ for $48 \mathrm{hrs}$. Zone of inhibition was measured for each plates and antibacterial activity was represented in terms of bacterial growth inhibited around the area where nanoparticles dose was applied.

\subsection{Cell cultures}

B16F10 cells were obtained from National Centre for Cell Science, Pune, India (NCCS) and used for the determination of the anticancer activity and cytotoxicity of $\mathrm{ZnO}$ NPs and commercial $\mathrm{ZnO}$ NPs. The cells were cultured in Minimal Essential Media supplemented with 10\% FBS, antibiotic (100U/ml) (Invitrogen, Thermo Fisher Scientific Corporation, Massachusetts, USA) in a humidified atmosphere of $5 \% \mathrm{CO}_{2}$ at $37^{\circ} \mathrm{C}$ temperature.

\subsection{Cell viability assay}

Skin melanoma cell line B16F10 were plated into 96 well plated at a density of 1 x $10^{5}$ cells/well. After 80\% of confluence, the cells were treated with different doses (1-8\%) of green synthesized and commercial $\mathrm{ZnO}$ NPs (w/v) respectively and incubated for 4 hours. After the incubation period the experimental medium was removed and the cells were washed with phosphate buffer saline, followed by incubation with MTT working solution $(100 \mu \mathrm{g} / \mathrm{ml})$ for $3 \mathrm{hrs} .100 \mu \mathrm{l}$ of DMSO was added into each well of the 96 well plates and the cell viability was measured by the absorbance at $595 \mathrm{~nm}$ by micro-plate reader. 
Green Synthesis of Zinc Oxide Nanoparticles via Algal Route and its Action on Cancerous Cells and Pathogenic Microbes

\subsection{Acridine Orange EtBr assay}

B16F10 cells were plated into 24 well plated at a density of $1 \times 10^{6}$ cells/well. After $80 \%$ of confluence, the cells were treated with 3\% and 5\% green synthesized and commercial ZnO NPs respectively and incubated for 4 hours. After the incubation period the cultured medium was removed and the cells were washed with phosphate buffer saline. Then the cells were incubated with Acridine Orange-EtBr working solution $(100 \mu \mathrm{g} / \mathrm{ml})$ for 30 mins followed by washing with phosphate buffer saline. The images were observed in fluorescence Olympus microscope and were captured using Camedia software (E- 20P 5.0Megapixel). The percentage for dead and live cells was quantified using at least five fields of cells for each treatment.

\subsection{Estimation of Reactive Oxygen Species (ROS)}

To determine ROS generation, B16F10 cells were plated into 96 well plated at a density of $1 \times 10^{5}$ cells /well. After $80 \%$ of confluence, the cells were treated with $3 \%$ and $5 \%$ of green synthesized and commercial $\mathrm{ZnO}$ NPs respectively and incubated for 4 hours. Experimental media was discarded from each seeded well of the 96-well plate and $25 \mu \mathrm{M} \mathrm{H}_{2}$ DCFDA in PBS for 30min and was incubated according to the protocol of Image-iTTM LIVE Green Reactive Oxygen Species Detection Kit (Invitrogen, USA). The images were observed in fluorescence Olympus microscope and were captured using Camedia software (E-20P 5.0Megapixel). The percentage for ROS generating cells was quantified with respect to phase images where at least five fields of cells were quantified for each treatment.

\subsection{Statistical analysis}

Experiments were repeated for at least three times independently. The statistical analysis of the data was done using GraphPad Instat-3 (version 3.06, San Diego, California, USA) software. Comparison between groups was performed using one-way analysis of variance (ANOVA) followed by Student-Newman-Keuls T-test. Data were fitted using Sigma plot (version11.0, GmbH, Germany) represented as means \pm SEM. $\mathrm{p}$ $<0.05$ was accepted as level of significance; $* * * *$ very highly significant $\mathrm{p}<0.0001$, *** highly significant $\mathrm{p}<0.001 ; * *$ significant $\mathrm{p}<0.01 ; *$ less significant $\mathrm{p}<0.05 ;$ NS not significant for $\mathrm{p}>0.05$.

\section{Results and discussions}

\subsection{XRD analysis}

Synthesized zinc oxide nanoparticles had an average particle size of about $3.1 \mathrm{~nm}$ (Fig 1) and $23.4 \mathrm{~m}^{2} / \mathrm{g}$ surface area. XRD analysis revealed peak positions with $2 \theta$ values at $31.8^{\circ}, 34.5^{\circ}, 36.3^{\circ}, 47.59^{\circ}, 56.63^{\circ}$, $62.89^{\circ}, 66.4^{\circ}, 67.98^{\circ}, 69.09^{\circ}$ and $76.98^{\circ}$ respectively with (100), (002), (101), (102), (110), (103), (002), (112), (201) and (202) planes are in good agreement with standard $\mathrm{ZnO}$ as obtained from the International Center of Diffraction Data card (JCPDS-36-1451) [26] confirming the formation of a crystalline monoclinic structure.

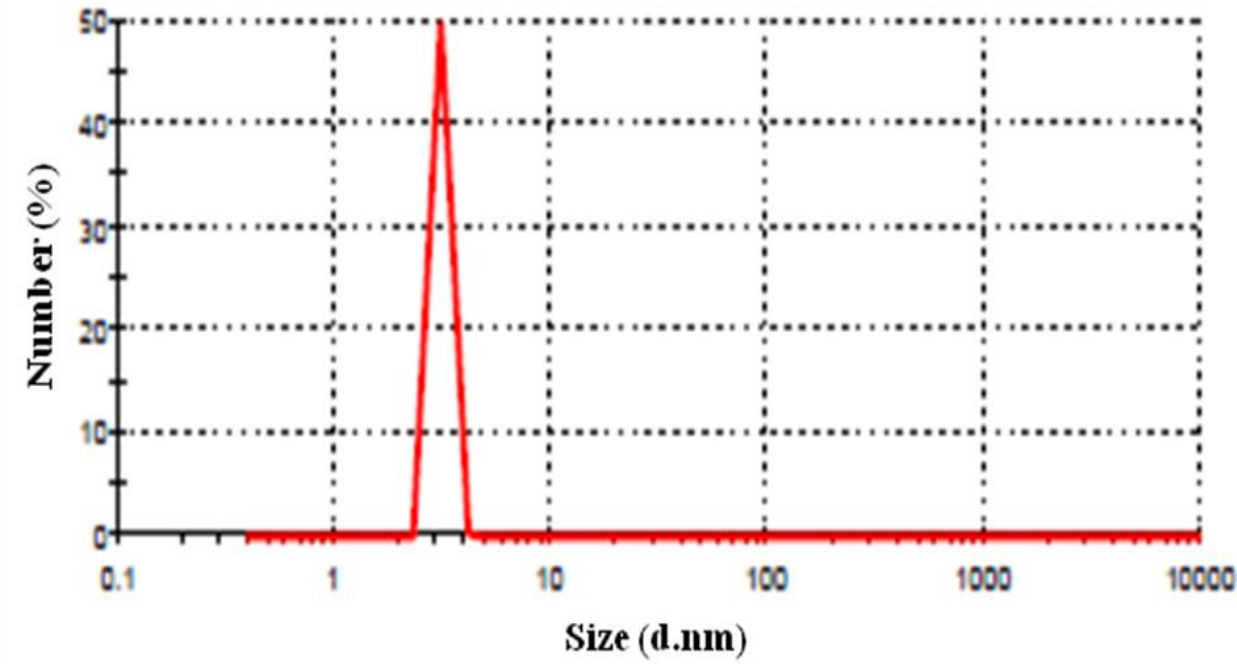

Figure 1: Particle size distribution of green synthesized ZnO NPs. 
Priyankari Bhattacharya et al., Adv. Nan. Res.; Vol. 3, Issue 1, pp: 15-27, 2020

Diffraction peaks of other phases were not present thereby confirming formation of pure phase of zinc oxide nanoparticles (Fig 2).

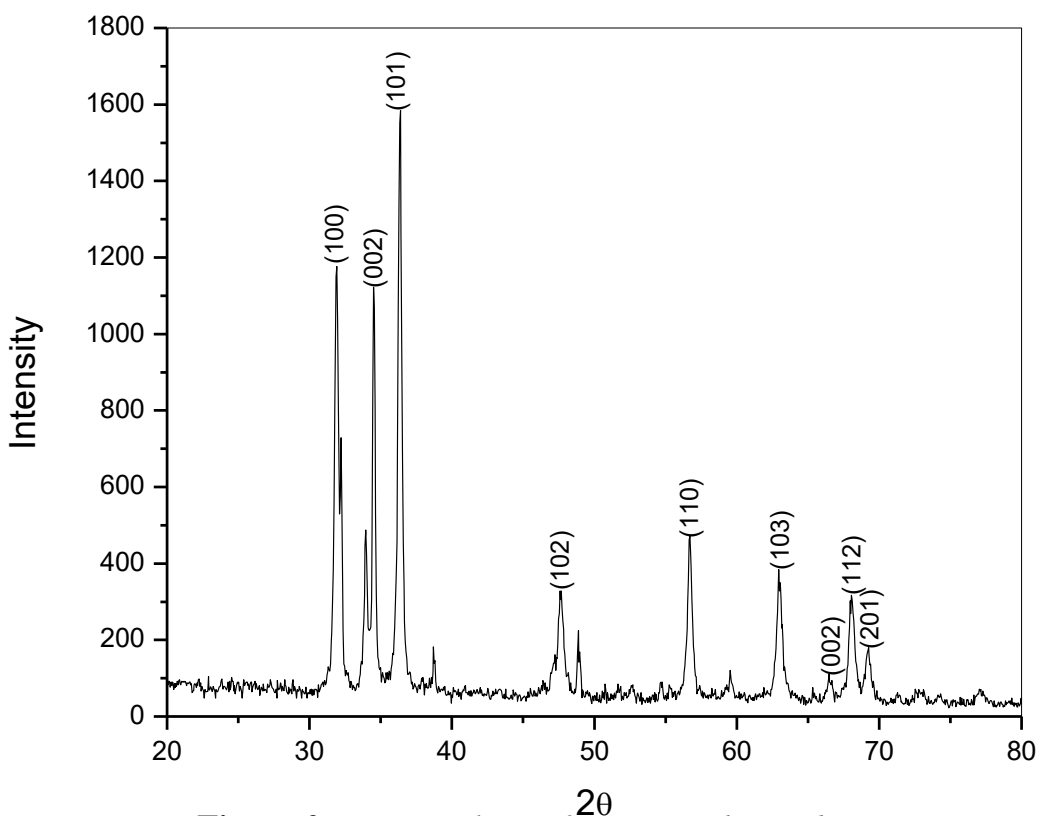

Figure 2: XRD analysis of green synthesized ZnO NPs.
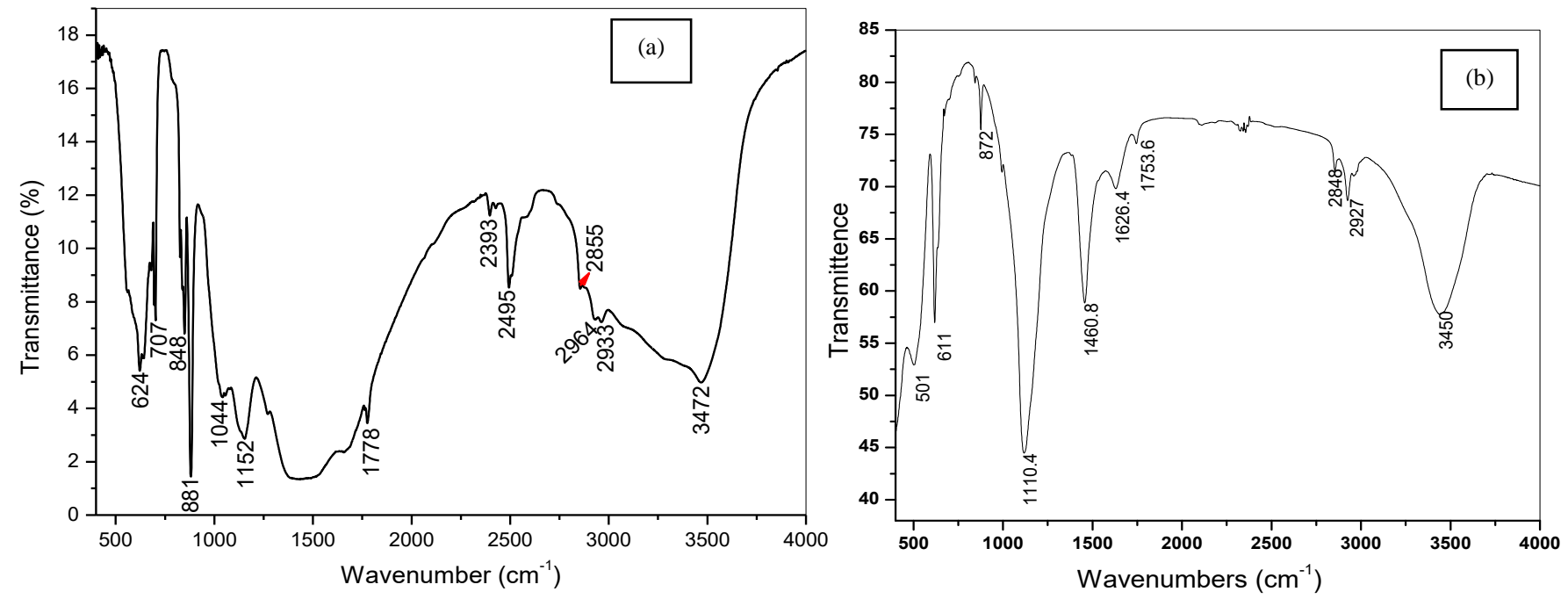

Figure 3: FTIR analysis of (a) algal cells and (b) ZnO NPs synthesized with algal extract.

\subsection{FTIR analysis}

FTIR spectrum of algae extract from Fig 3 revealed spectrum range at $3471 \mathrm{~cm}^{-1}$ which corresponded to presence of bonded and non-bonded O-H group. Peaks at $2964 \mathrm{~cm}^{-1}$ and $2933 \mathrm{~cm}^{-1}$ were due to asymmetric CH2-, symmetric CH3 and -CH2- stretching vibrations. Peaks at $2855 \mathrm{~cm}^{-1}$ and $1152 \mathrm{~cm}-{ }^{-1}$ corresponded to $\mathrm{CH} 2$-stretching of lipid and carbohydrate. IR vibrations at $1784 \mathrm{~cm}^{-1}$ was due to $\mathrm{C}=\mathrm{O}$ stretching of esters. $881 \mathrm{~cm}^{-1}, 848 \mathrm{~cm}^{-1}$ and $707 \mathrm{~cm}^{-1}$ corresponded to $\mathrm{C}-\mathrm{H}$ bending and peak at $624 \mathrm{~cm}^{-1}$ was due to bending vibration of $\mathrm{C}-\mathrm{OH}$ and $-\mathrm{COO}$. Result indicates that phytochemicals present in algal extract were responsible for synthesis of zinc oxide nanoparticles. IR peaks of $\mathrm{ZnO}$ at $3450 \mathrm{~cm}^{-1}, 2927 \mathrm{~cm}-$ ${ }^{1}, 2848 \mathrm{~cm}^{-1}$ corresponded to stretching vibration of bonded and non-bonded O-H groups, asymmetric $\mathrm{CH} 2$, symmetric $-\mathrm{CH} 3$, and $\mathrm{CH} 2$ - stretching vibrations, $-\mathrm{OH}$ stretches respectively. These peaks were present in extract which shifted in $\mathrm{ZnO}$ particles indicating their role in metal oxide formation. Peaks at $1753.6 \mathrm{~cm}^{-1}$ and $1626.4 \mathrm{~cm}^{-1}$ corresponded to $\mathrm{C}=\mathrm{O}$ carboxylic acid stretch and aromatic $\mathrm{C}=\mathrm{C}$ stretching. 
Green Synthesis of Zinc Oxide Nanoparticles via Algal Route and its Action on Cancerous Cells and Pathogenic Microbes

There was a shift in peak from $1152 \mathrm{~cm}^{-1}$ of extract to $1110.4 \mathrm{~cm}^{-1}$ in metal oxide which corresponded to C-O-C stretching suggesting role of carbohydrate in formation of metal oxide. IR peaks at $872 \mathrm{~cm}^{-1}$ and $611 \mathrm{~cm}^{-1}$ corresponded to $\mathrm{O}-\mathrm{H}$ asymmetric stretching vibration and $\mathrm{C}-\mathrm{N}$ bond respectively. Peak region from $400-600 \mathrm{~cm}^{-1}$ is that of ZnO NPs and from IR data, peak at $501 \mathrm{~cm}^{-1}$ corresponded to ZnO NPs [27].

\subsection{FESEM and TEM analysis}

Fig 4 depicted the FESEM micrographs of the nanoparticles It was observed that rod like nano structure was formed having dimension of 40-60nm. The micrographs also showed presence of some larger particles due to agglomeration with more or less uniform size, shape and morphology. Phase purity was confirmed from EDX analysis where broad peaks of $\mathrm{Zn}$ were found. TEM analysis (Fig 5) revealed rod like structure with minimum agglomerated zinc oxide nanoparticles embedded in algal matrix. SAED (Selected area electron diffraction) pattern revealed diffraction rings of monoclinic $\mathrm{ZnO}$ [28].
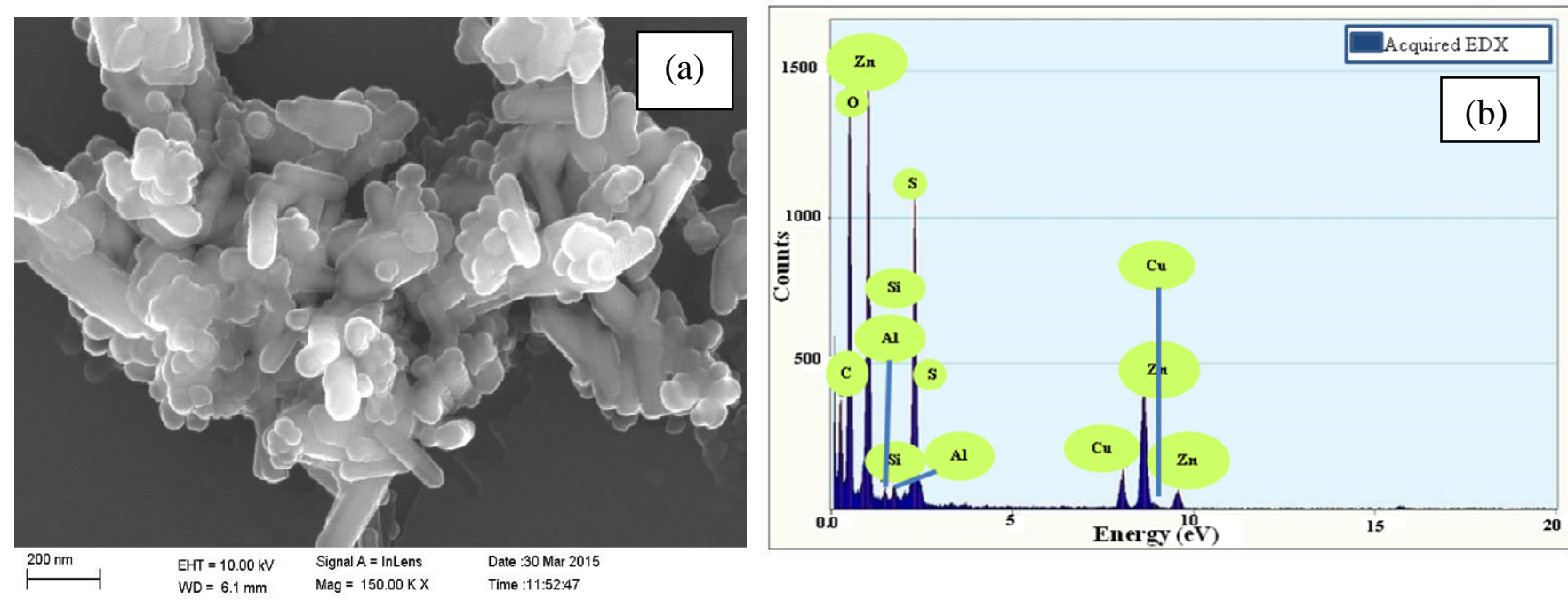

Figure 4: FESEM and (b) EDX analysis of green synthesized ZnO NPs
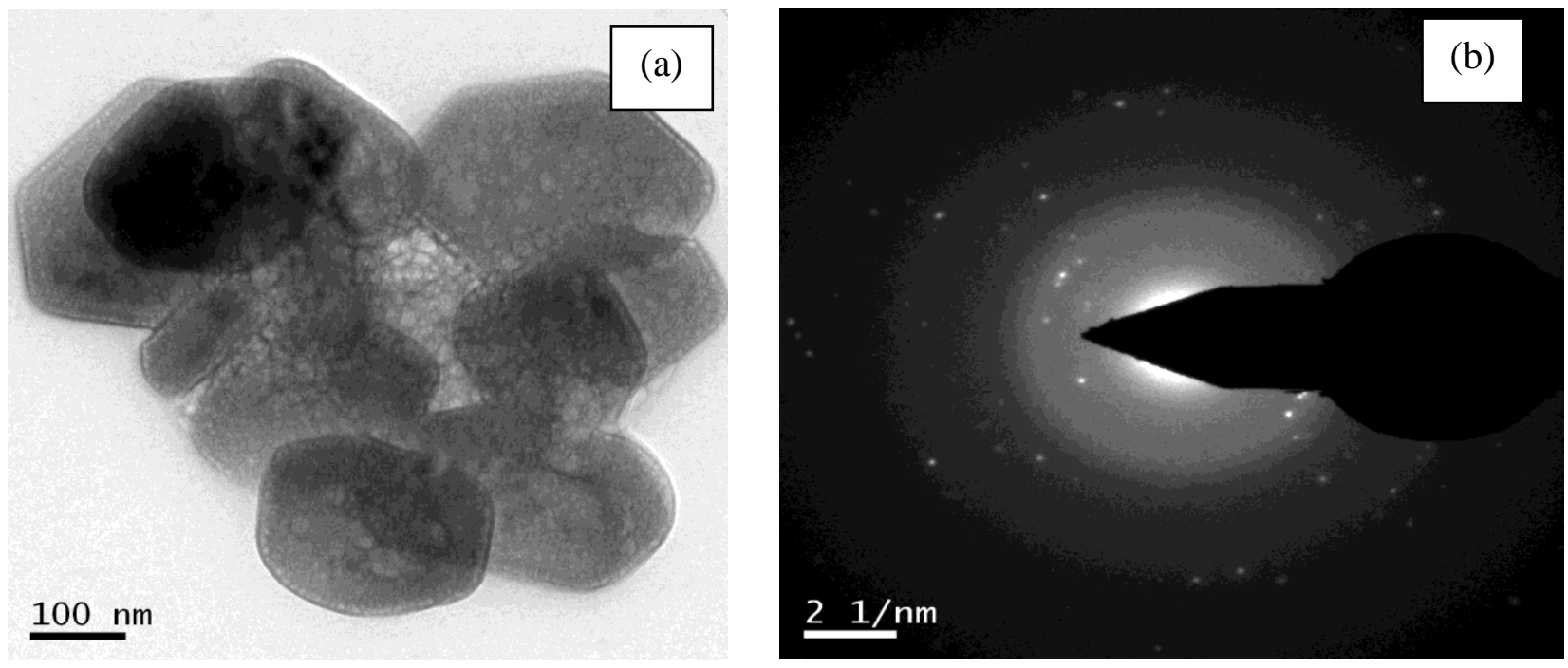

Figure 5: (a) TEM image (b) SAED pattern of green synthesized ZnO NPs. 


\subsection{Antimicrobial activity of green synthesized $\mathrm{ZnO}$ NPs}

The results as evident from Fig 6, suggested that $\mathrm{ZnO}$ NPs was effective against both gram-positive and gram-negative bacteria. Zone of inhibition (ZOI) exhibited by Pseudomonas aeruginosa for disc diffusion and well diffusion assay showed around 10-22 mm ZOI as compared to control while Staphylococcus aureus showed 9-12mm ZOI for disc diffusion assay and well diffusion assay. Nanoparticles exhibited strong antibacterial activity against both gram positive and gram-negative bacteria. Antimicrobial activity of zinc oxide nanoparticles is size dependent i.e. with reducing particle size, activity increases. Possible cause of action might be due to membrane damage between nanoparticles and cell surfaces resulting in production of reactive oxy gen species. Xie et al. (2011) observed significant change in cell morphology of C. jejuni when treated with $\mathrm{ZnO}$ particles by SEM analysis [29].

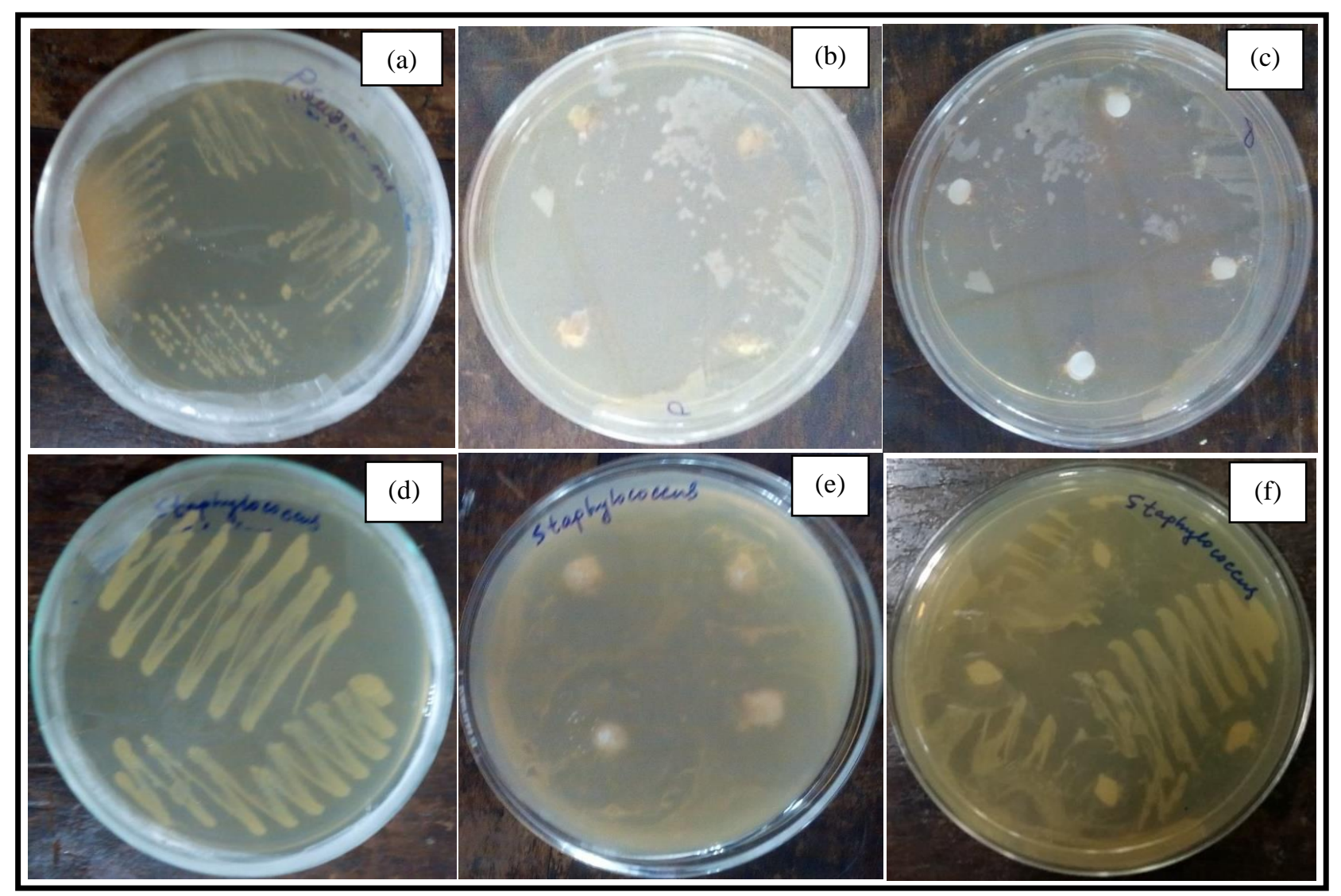

Figure 6: Antimicrobial activity of green synthesized $\mathrm{ZnO} N P s$

\subsection{ZnO NPs treatment reduced viability of skin cancer (melanoma) cells}

To examine whether green synthesized ZnO NPs treatment affects the cellular proliferation/viability, MTT assay was performed, with exposure time of $4 \mathrm{hrs}$ with increasing concentration (1\%-8\%) of both green synthesized ZnO NPs and commercial ZnO NPs, on B16F10 melanoma cells. The cell viability was measured from the absorbance at $595 \mathrm{~nm}$ by micro-plate reader. Results showed that B16F10 cells were more sensitive to green synthesized $\mathrm{ZnO} N P$ s treatments and exhibited a greater reduction in viability of cells than commercial $\mathrm{ZnO}$ treatments (Figure 7). With increasing dose of the $\mathrm{ZnO} N P$, percentage viability of cells gradually reduced significantly. $3 \%$ of dose of $\mathrm{ZnO}$ NPs showed $50 \%$ decrease in cellular viability (ED50), while commercial $\mathrm{ZnO}$ exhibited ED50 at 6\% of doses, indicating superior affectivity of green synthesized $\mathrm{ZnO}$ NPs over commercial $\mathrm{ZnO}$ NPs on cultured cancer cells. The differences in the effectiveness of synthesized ZnO NPs and commercial ZnO NPs in cancer cell killing, however gradually 
Green Synthesis of Zinc Oxide Nanoparticles via Algal Route and its Action on Cancerous Cells and Pathogenic Microbes

reduced with increasing doses (more than 6\%), which might have resulted from increased toxicity (Figure 7). Therefore, dose of 3\% and 5\% was selected for assessing cellular death and ROS activity. Namvar et al., observed green synthesized ZnO NPs inhibited proliferation of murine cancer cells in dose and time dependant manner, although normal cells were unaffected [24]. Bai et al., observed similar trend where increasing the concentration of $\mathrm{ZnO} N$ Ps resulted decrease in cellular viability of ovarian cancer cells [30]. The authors suggested that $\mathrm{ZnO}$ NPs results in reduced mitochondrial function and leakage of lactate dehydrogenase in addition to generation of ROS. Similar dose dependant cellular viability was observed by Wang et al., in pulmonary adenocarcinoma cell line LTEP-a-2 [31].

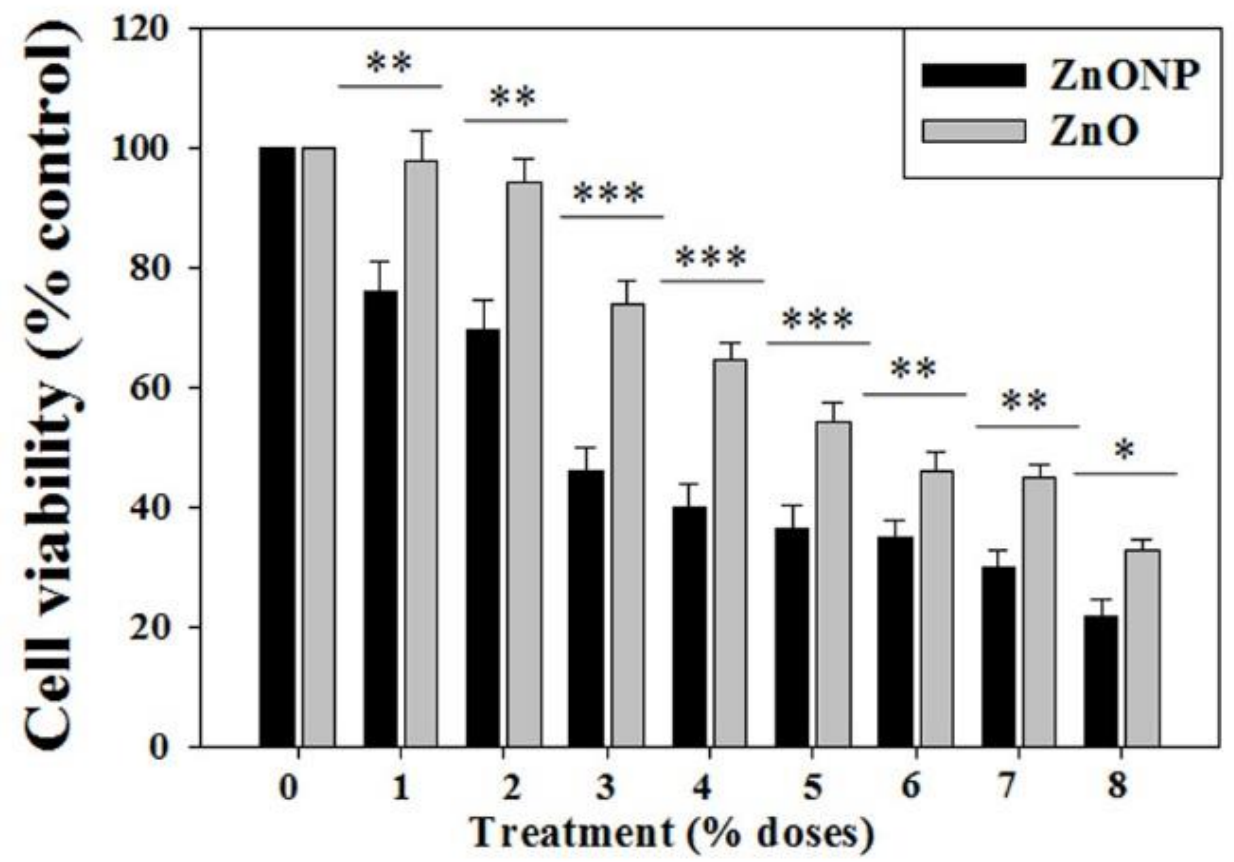

Figure 7: Cytotoxicity of green synthesized and commercial ZnO NPs for 4 hrs in B16F10 melanoma cells (*** highly significant $p<0.001$; ** significant $p<0.01$; * less significant $p<0.05)$.

\subsection{ZnO NPs treatment increased cellular death in skin cancer cells}

Acridine orange/EtBr staining was performed for differentiating live cells from dead cells on the basis of membrane integrity. Acridine orange stains both live and dead cells, whereas ethidium bromide stains only cells that have lost membrane integrity. The cells were treated with 3\% and 5\% of green synthesized $\mathrm{ZnO}$ NPs and commercial ZnO NPs and incubated for 4 hours. The cells were then incubated with Acridine Orange-EtBr working solution $(100 \mu \mathrm{g} / \mathrm{ml})$ for 30 mins followed by washing with phosphate buffer saline. The images were observed in fluorescence Olympus microscope. It was observed that intact cell membranes (control) showed green fluorescence due to AO uptake by double stranded DNA but apoptotic cells had condensed chromatin and damaged cell membrane appeared clumps of green fluorescent spots with uniform orange nuclei [25]. ZnO NPs treatments induced cellular apoptosis in a dose dependant manner as gradual increase in percentage of dead cells with increasing doses of $\mathrm{ZnO}$ NPs (Figure 8a). When quantified, it was found that the survival rates were $\sim 40 \%$ and $\sim 30 \%$ for $3 \%$ and $5 \%$ doses of green synthesized ZnO NPs treatments respectively, whereas with same doses of commercial ZnO NPs, the cell survival rate were around $80 \%$ and $70 \%$ respectively (Figure $8 \mathrm{~b}$ ). Similar trend was observed by Namvar et al. and Rahman et al. [24]- [32]. Similar behaviour was also depicted by CuO NPs in mammalian human gastric epithelium (AGS) and Chinese hamster ovarian (CHO) cell lines [25]. 
(a)
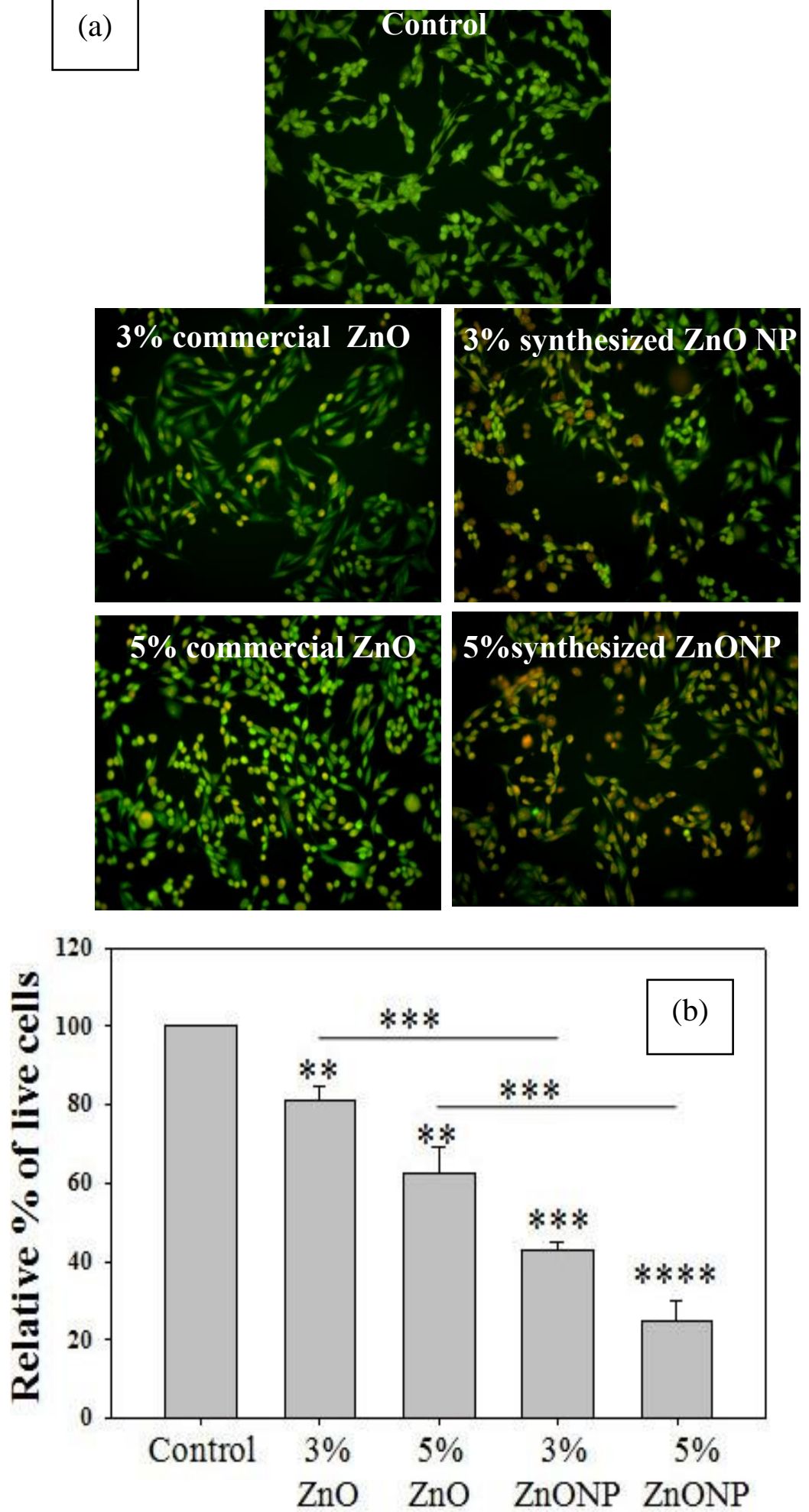

Figure 8: (a) Representative microphotographs showing live (green) and apoptotic cells (orange) after exposure of B16F10 melanoma cells to various concentration of green synthesized and commercial ZnO NPs; (b) Quantification of relative percentage of live cells on 4 hours exposure to various concentrations (3\%and $5 \%$ ) of of green synthesized and commercial ZnO NPs in B16F10 cells (**** very highly significant $p<$ $0.0001, * * *$ highly significant $p<0.001$; ** significant $p<0.01$; * less significant $p<0.05$ ). 
Green Synthesis of Zinc Oxide Nanoparticles via Algal Route and its Action on Cancerous Cells and Pathogenic Microbes

\subsection{ZnO NPs induced oxidative stress in skin cancer cells}

To elucidate how cellular death and viability are associated with $\mathrm{ZnO}$ NPs induced oxidative stress, the authors looked into live cellular ROS status during nanoparticle treatment. Generation of intracellular ROS causes decrease in antioxidative system of the cell which in turn results in oxidative damage of cells and ultimate cell death [30]. In this study it was observed that $\mathrm{ZnO} \mathrm{NP}$ treatments increased the production of ROS to a great extent. Significantly higher numbers of ROS generating cells (in fluorescent dye) was observed in green synthesized $\mathrm{ZnO}$ NPs treatments in comparison to commercial ZnO NPs. Nanoparticles showed dose dependent elevation of ROS generating cells (Figure 9a). The images were observed in fluorescence Olympus microscope and were captured using Camedia software (E20P 5.0Megapixel). With the doses of $3 \%$ and $5 \%$ respectively, the percentage of ROS generating cells were $45 \%$ and $55 \%$ respectively (Figure 9b), whereas with the same doses commercial $\mathrm{ZnO}$ NPs exhibited significantly less ROS generation $\quad(\sim 20 \%$ and $30 \%$ respectively), indicating superior affectivity of green synthesized $\mathrm{ZnO}$ NPs over commercial ZnO NPs in inducing oxidative stress mediated cellular death of cultured melanoma cells. The excessive generation of ROS due to damage of mitochondrial electron transport chain causes loss of balance in protein activity of cells and ultimate apoptosis [6].
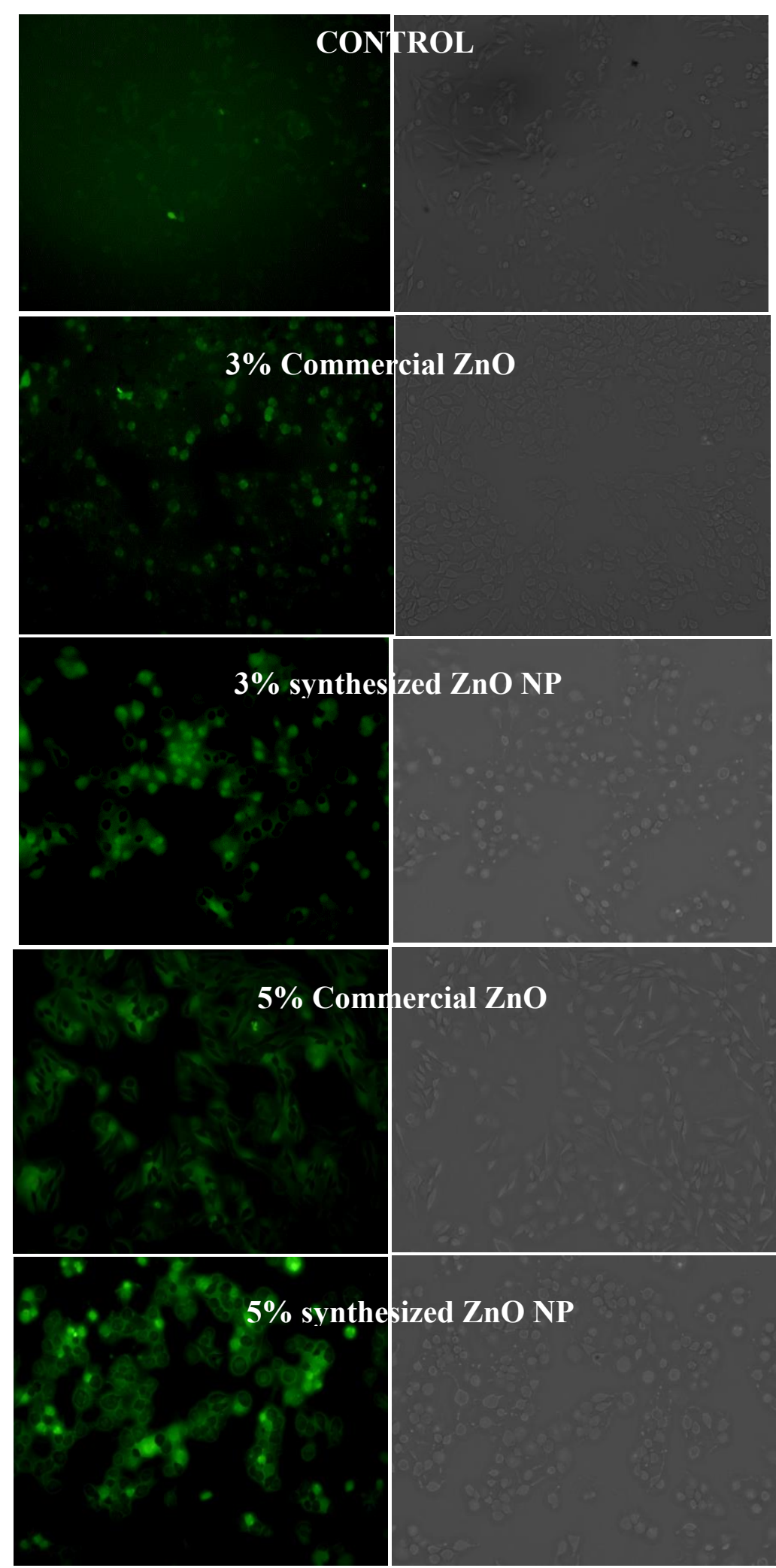

Figure 9 (a): Effect of green synthesized and commercial ZnO NPs on ROS generation in B16F10 cells; Representative microphotographs showing of green synthesized and commercial $\mathrm{ZnO}$ NPs induced ROS generation in B16F10 cells. 
Priyankari Bhattacharya et al., Adv. Nan. Res.; Vol. 3, Issue 1, pp: 15-27, 2020

Bai et al. also observed oxidative stress mediated ovarian cancer cell death by ZnO NPs. ROS mediated cancer cell death was also observed by other nanoparticles like silver, palladium, graphene etc. [30]-[33].

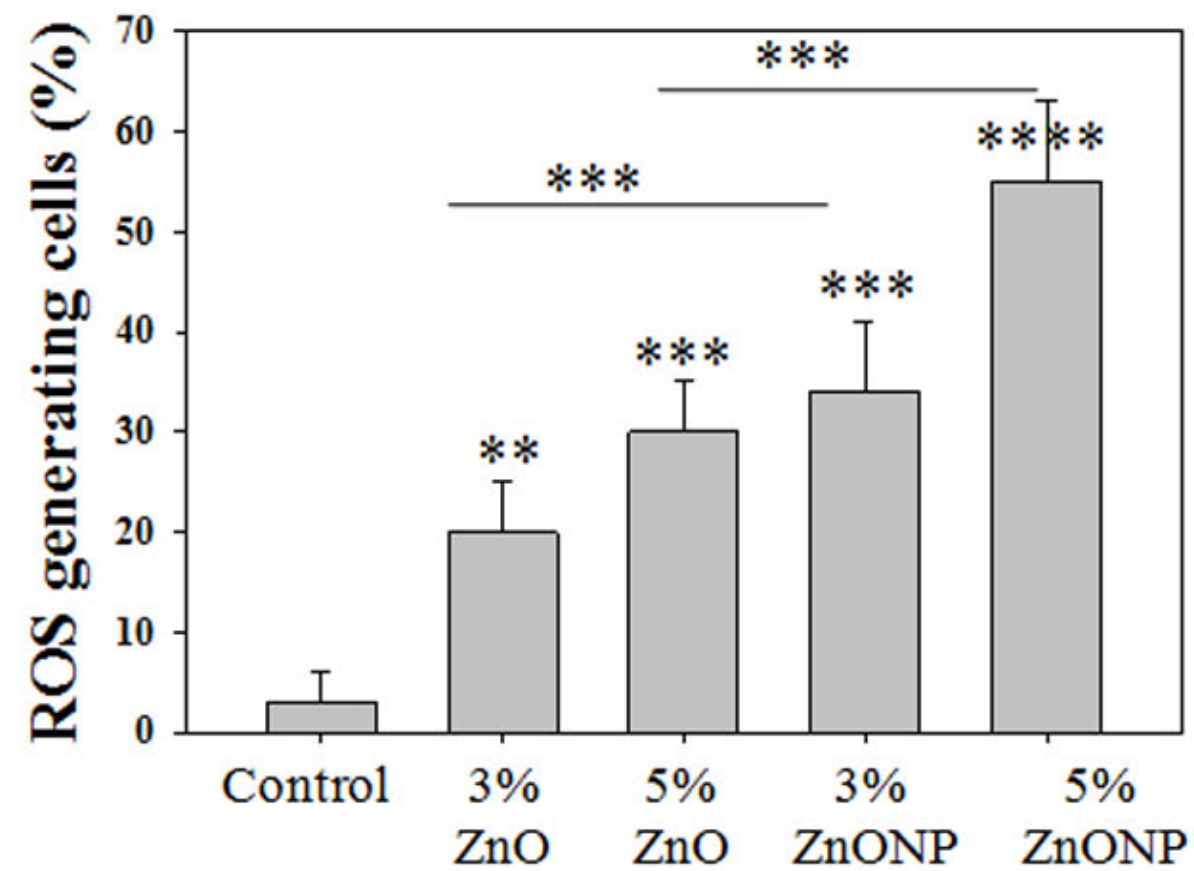

Figure 9 (b): Effect of green synthesized and commercial ZnO NPs on ROS generation in B16F10 cells; Quantification of ROS generating cells on 4 hours exposure to various concentrations (3\% and 5\%) of of green synthesized and commercial ZnO NPs in B16F10 cells (**** very highly significant $p<0.0001$, *** highly significant $p<0.001 ; * *$ significant $p<0.01$; * less significant $p<0.05$ ).

\section{Conclusion}

Attempts were undertaken for treatment of melanoma cells and pathogenic microbes using green synthesized zinc oxide nanoparticles using algal extract. Under optimized stirring conditions and algal dose, nanoparticles of about $3.1 \mathrm{~nm}$ were formed at $1 \mathrm{mM}$ substrate concentration. Antimicrobial activity of synthesized nanoparticles was observed against gram positive as well as gram negative, pathogenic bacteria i.e. Pseudomonas and Staphylococcus sp. respectively. The study explored the potential anticancer activity of synthesized $\mathrm{ZnO}$ NPs on B16F10 melanoma cell line and compared the results with commercially available $\mathrm{ZnO}$ NPs. $50 \%$ cell death was observed with 3\% of green synthesized ZnO NPs dose whereas for commercial ZnO NPs ED50 was observed at $6 \%$ of doses. 45\% cells exhibited ROS generation with 3\% dose of green synthesized ZnO NPs which was only $\sim 20 \%$ for same dose of commercial ZnO NPs. The results thus suggest higher efficiency of green synthesized $\mathrm{ZnO}$ NPs on cancer cell death with lower doses having less toxicity and potential application for oxide-based nanoparticles as chemotherapeutics as compared with commercial $\mathrm{ZnO}$ NPs. However, in vivo studies are warranted to understand the effectiveness of green synthesized $\mathrm{ZnO}$ NPs against melanoma tumor models to evaluate the therapeutics potential.

\section{Declarations}

\subsection{Acknowledgments}

The authors would like to thank Department of Science and Technology (SERB, Govt. Of India) vide. PDF/2016/003273 for providing financial support to carry out the experimental work under their funding project. 
Green Synthesis of Zinc Oxide Nanoparticles via Algal Route and its Action on Cancerous Cells and Pathogenic Microbes

\title{
5.2 Funding source
}

\author{
$\mathrm{PDF} / 2016 / 003273$, DST
}

\subsection{Competing Interests}

There exists no potential conflict of interest

\section{How to Cite this Article:}

P. Bhattacharya, K. Chatterjee, S. Swarnakar, and S. Banerjee, "Green Synthesis of Zinc Oxide Nanoparticles via Algal Route and its Action on Cancerous Cells and Pathogenic Microbes", Adv. Nan. Res., vol. 3, no. 1, pp. 15-27, Jul. 2020. https://doi.org/10.21467/anr.3.1.15-27

\section{References}

[1] T. Liedl, B. Hogberg, J. Tytell, D.E. Ingber, W.M. Shih, "Self-assembly of three-dimensional prestressed tensegrity structures from DNA," Nature Nanotechnology, vol. 5, no. 7, pp.520-524, Nat. Nanotechnol. June, 2010. doi: 10.1038/nnano.2010.107. Epub.

[2] W. Gao, J.M. Chan, O.C. Farokhzah, "pH-responsive nanoparticles for drug delivery”, Molecular Pharmaceutics, vol. 7, no. 6, pp. 19131920. Mol Pharm. October, 2010. doi: 10.1021/mp100253e.

[3] R.L. Spears, R.E. Cameraon, “Carbon nanotubes for orthopaedic implants", International Journal of Material Forming, vol. 1, pp. 127133, Int J Mater Form, July, 2008. https://doi.org/10.1007/s12289-008-0374-8.

[4] M. Martinez-Carmona, Y. Gun'ko, M. Vallet-Regi, "ZnO nanostructures for drug delivery and theranostic applications". Nanomaterials. vol. 8, no. 4, pp. 1-27, April, 2018. doi: 10.3390/nano8040268.

[5] M.P. Vinardell, M. Mitjans, “Antitumor activities of metal oxide nanoparticles”, Nanomaterials, vol. 5, no. 2, pp. 1004-1021, June, 2015. https://doi.org/10.3390/nano5021004.

[6] J. Jiang, J. Pi, J. Cai, “The Advancing of Zinc Oxide Nanoparticles for Biomedical Applications”,Bioinorganic Chemistry and Appplications, vol. 2018, pp. 1-18, July, 2018, Bioinorg Chem Appl. doi: 10.1155/2018/1062562.

[7] R. J. Vandebriel, W.H.D. Jong, "A review of mammalian toxicity of ZnO nanoparticles", Nanotechnology, Science and Application, vol. 5, pp. 61-71. Nanotechnol Sci Appl. August, 2012. doi: 10.2147/NSA.S23932.

[8] F. Caputo, M. de Nicola, L. Ghibelli, "Pharmacological potential of bioactive engineered nanomaterials", Biochemical Pharmacology, vol. 92, no 1, pp. 112-130. Biochem Pharmacol August, 2014. doi: 10.1016/j.bcp.2014.08.015.

[9] Y. Zhang, T.R. Nayak, H. Hong, W. Cai, "Biomedical applications of zinc oxide nanomaterials", Current Molecular Medicine, vol. 13, pp. 1633-1645, Curr Mol Med. December, 2013. doi : 10.2174/1566524013666131111130058.

[10] K.W. Ng, S.P.K Khoo, B.C. Heng, M.I. Setyawati, E. C. Tan, X. Zhao, S. Xiong, W. Fang, D. T. Leong, J.S.C. Loo, "The role of the tumor suppressor 533 pathway in the cellular DNA damage response to zinc oxide nanoparticles", Biomaterials, vol. 32, no. 32, pp. 8218-8225, November, 2011. http://dx.doi.org/10.1016/j.biomaterials.2011.07.036.

[11] J. Wang, S. Gao, S. Wang, Z. Xu, L. Wei, "Zinc oxide nanoparticles induce toxicity in CAL 27 oral cancer cell lines by activating PINK1/Parkin-mediated mitophagy”, The International Journal of Nanomedicine, vol. 13, pp. 3441-3450, Int J Nanomedicine June, 2018. doi: $10.2147 / \mathrm{IJN}$. S165699.

[12] R. Tanino, Y. Amano, X. Tong, R. Sun, Y. Tsubata, M. Harada, Y. Fujita, T. Isobe, “Anticancer Activity of ZnO Nanoparticles against Human Small-Cell Lung Cancer in an Orthotopic Mouse Model”, Molecular Cancer Therapeutics, vol. 19, pp. 1-11, Mol Cancer Ther, November, 2020. doi: 10.1158/1535-7163.MCT-19-0018.

[13] M.P. Vinardell, M. Mitjans, "Antitumor activities of metal oxide nanoparticles", Nanomaterials, vol. 5, no. 2, pp. 1004-1021, June, 2015. https://doi.org/10.3390/nano5021004.

[14] R. Wahab, S. Dwivedi, A. Umar, S. Singh, I.H. Hwang, H. S. Shin, J. Musarrat, A.A. Al-Khedhairy, Y.S. Kim, "ZnO nanoparticles induce oxidative stress in Cloudman S91 melanoma cancer cells”, Journal of Biomedical Technology, vol. 9, no. 3, pp.441-449, J Biomed Nanotechnol, March, 2013. doi: 10.1166/jbn.2013.1593.

[15] R. Wahab, N.K. Kaushik, N. Kaushik, E.H. Choi, A. Umar, S. Dwivedi, J. Musarrat, A.A. Al-Khedhairy, "ZnO nanoparticles induces cell death in malignant human T98G gliomas, KB and non-malignant HEK cells", Journal of Biomedical Nanotechnology, vol. 9 no.7, pp. 1181-1189, J Biomed Nanotechnol. July, 2013. doi: 10.1166/jbn.2013.1652.

[16] R. Wahab, M.A. Siddiqui, Q. Saquib, S. Dwivedi, J. Ahmad, J., Musarrat, A.A. Al-Khedhairy, H.S., Shin, "ZnO nanoparticles induced oxidative stress and apoptosis in HepG2 and MCF-7 cancer cells and their antibacterial activity" Colloids and Surfaces, B, Biointerfaces, vol. 117, pp. 267-276. Colloids Surf B. Biointerfaces, May, 2014. doi: 10.1016/j.colsurfb.2014.02.038.

[17] S.S. Elshama, E. M.E. Abdallah, R.I. Abdel-Karim, "Zinc Oxide Nanoparticles: Therapeutic Benefits and Toxicological Hazards", The Open Nanomedicine Journal, vol. 5, pp. 16-22, June, 2018, doi: 10.2174/1875933501805010016.

[18] L. Mielcarz-Skalska, B. Smolińska, "Zinc and nano-ZnO - influence on living organisms", Biotechnology and Food Science, vol. 81, no. 2, pp. 93-102, Biotechnol Food Sci, July, 2017. http://www.bfs.p.lodz.pl/.

[19] T.V. Kolekar, S.S. Bandgar, S.S. Shirguppikar, V.S. Ganachari, "Synthesis and characterization of ZnO nanoparticles for efficient gas sensors", Archives of Applied Science Research, vol. 5, no. 6, pp. 20-28. Arch Appl Sci Res, 2013. doi: 10.1166/jnn.2018.14651

[20] R. Dobrucka, J. Długaszewska, "Biosynthesis and antibacterial activity of ZnO nanoparticles using Trifolium pratense flower extract", Saudi Journal of Biological Sciences, vol., 23, no. 4, pp. 517-523, Saudi J Biol Sci, July, 2016. https://doi.org/10.1016/j.sjbs.2015.05.016.

[21] P. Rajiv, S. Rajeshwari, R. Venckatesh, "Bio-Fabrication of zinc oxide nanoparticles using leaf extract of Parthenium hysterophorus L. and its size-dependent antifungal activity against plant fungal pathogens" Spectrochimica Acta Part A: Molecular and Biomolecular Spectroscopy, vol. 112, pp. 384-387, Spectrochim. Acta Part A Mol Biomol Spectrosc, August, 2013. doi: 10.1016/j.saa.2013.04.072. 
Priyankari Bhattacharya et al., Adv. Nan. Res.; Vol. 3, Issue 1, pp: 15-27, 2020

[22] S. Vijayakumar, G. Vinoj, B. Malaikozhundan, S. Shanthi, B. Vaseeharan, "Plectranthus amboinicus leaf extract mediated synthesis of zinc oxide nanoparticles and its control of methicillin resistant Staphylococcus aureus biofilm and blood sucking mosquito larva", Spectrochimica Acta Part A: Molecular and Biomolecular Spectroscopy, vol. 137, pp. 886-891. Spectrochim Acta Part A Mol Biomol Spectrosc. February, 2015. doi: 10.1016/j.saa.2014.08.064.

[23] "Composition of the cellular envelopes of Anabaena cylindrica", J. H. Dunn, C. P. Wolk, Journal of Bacteriology, vol. 103, no. 1, pp. 153-158, J. Bacteriol. July, 1970.

[24] F. Namvar, H. S. Rahman, R. Mohamad, S. Azizi, P.M. Tahir, M. S. Chartrand, S. K. Yeap "Cytotoxic effects of biosynthesized zinc oxide nanoparticles on murine cell lines", Evidence-Based Complementary and Alternative Medicine, vol. 2015, pp. 1-11. January, 2015. http://dx.doi.org/10.1155/2015/593014.

[25] P. Bhattacharya, S. Swarnakar, S. Ghosh, S. Majumdar, S. Banerjee, Disinfection of drinking water via algae mediated green synthesized copper oxide nanoparticles and its toxicity evaluation, Journal of Environmental Chemical Engineering, vol. 7, no. 1, pp. 102867, February, 2019. https://doi.org/10.1016/j.jece.2018.102867.

[26] J. Chauhan, N. Shrivastav, A. Dugaya, D. Pandey, "Synthesis and Characterization of Ni and Cu Doped ZnO". Journal of Nanomedicine and Nanotechnology vol. 8, no. 2, pp. 1-8. J Nanomed Nanotechnol, 2017. doi: 10.4172/2157-7439.1000429.

[27] E. Preedia Babu, A. Subastri, A., Suyavaran, P. Lokeshwara Rao, M.K. Suresh, K. Jeevaratnam, C. Thirunavukkarasu, "Extracellularly synthesized ZnO nanoparticles interact with DNA and augment gamma radiation induced DNA damage through reactive oxygen species", RSC Advance, vol. 5, no 76, pp. 62067-62077, RSC Adv. July, 2015. doi: 10.1039/C5RA09935H.

[28] N. Narendhran, S. Rajeshwari, "Biogenic ZnO nanoparticles synthesized using L. aculeata leaf extract and their antifungal activity against plant fungal pathogens". Bulletin of Material Science, vol. 39, no. 1, pp. 1-5, Bull Mater Sci, January, 2016. doi: 10.1007/s12034-015-1136-0.

[29] Y. Xie, Y. He, P.L. Irwin, T. Jin, X. Shi, "Antibacterial activity and mechanism of action of zinc oxide nanoparticles against Campylobacter jejuni”, Applied and Environmental Microbiol, vol. 77, no. 7, pp. 2325-2331, Appl Environ Microbiol, April, 2011. doi: 10.1128/AEM.02149-10.

[30] D-P Bai, X-F Zhang, G-L Zhang, Y-F Huang, S. Gurunathan, "Zinc oxide nanoparticles induce apoptosis and autophagy in human ovarian cancer cells", International Journal of Nanomedicine, vol. 12, pp. 6521-6535, Int J Nanomedicine, September, 2017. doi: 10.2147/IJN.S140071.

[31] C. Wang, X. Hu, Y. Gao, Y. Ji, “ZnO nanoparticles treatment induces apoptosis by increasing intracellular ROS levels in LTEP-a-2 cells”, BioMed Research International, vol. 2015, pp. 1-9, August, 2015, Biomed Res Int. https://doi.org/10.1155/2015/423287.

[32] H. S. Rahman, A. Rasedee, A. B. Abdul, N. A. Zeenathul, H. H. Othman, S. K. Yeap, C. W. How, W. A. Ghani, W. N. Hafiza, "Zerumbone-loaded nanostructured lipid carrier induces G2/M cell cycle arrest and apoptosis via mitochondrial pathway in a human lymphoblastic leukemia cell line," International Journal of Nanomedicine, vol. 9, no. 1, pp. 527-538, Int J Nanomedicine, January, 2014. doi: 10.2147/IJN.S54346.

[33] S. Gurunathan, J.W. Han, J.H. Park, E. Kim, Y-J Choi, D-N Kwon, J-H Kim, "Reduced graphene oxide-silver nanoparticle nanocomposite: a potential anticancer nanotherapy", International Journal of Nanomedicine, vol. 10, pp. 6257-6276, Int J Nanomedicine, October, 2015. doi: 10.2147/IJN.S92449.

Publish your research article in AIJR journals-

* Online Submission and Tracking

* Peer-Reviewed

* Rapid decision

* Immediate Publication after acceptance

* Articles freely available online

* Retain full copyright of your article.

Submit your article at journals.aijr.in
Publish your books with AIJR publisher-

* Publish with ISBN and DOI.

* Publish Thesis/Dissertation as Monograph.

* Publish Book Monograph.

* Publish Edited Volume/ Book.

* Publish Conference Proceedings

* Retain full copyright of your books.

Submit your manuscript at books.aijr.org 